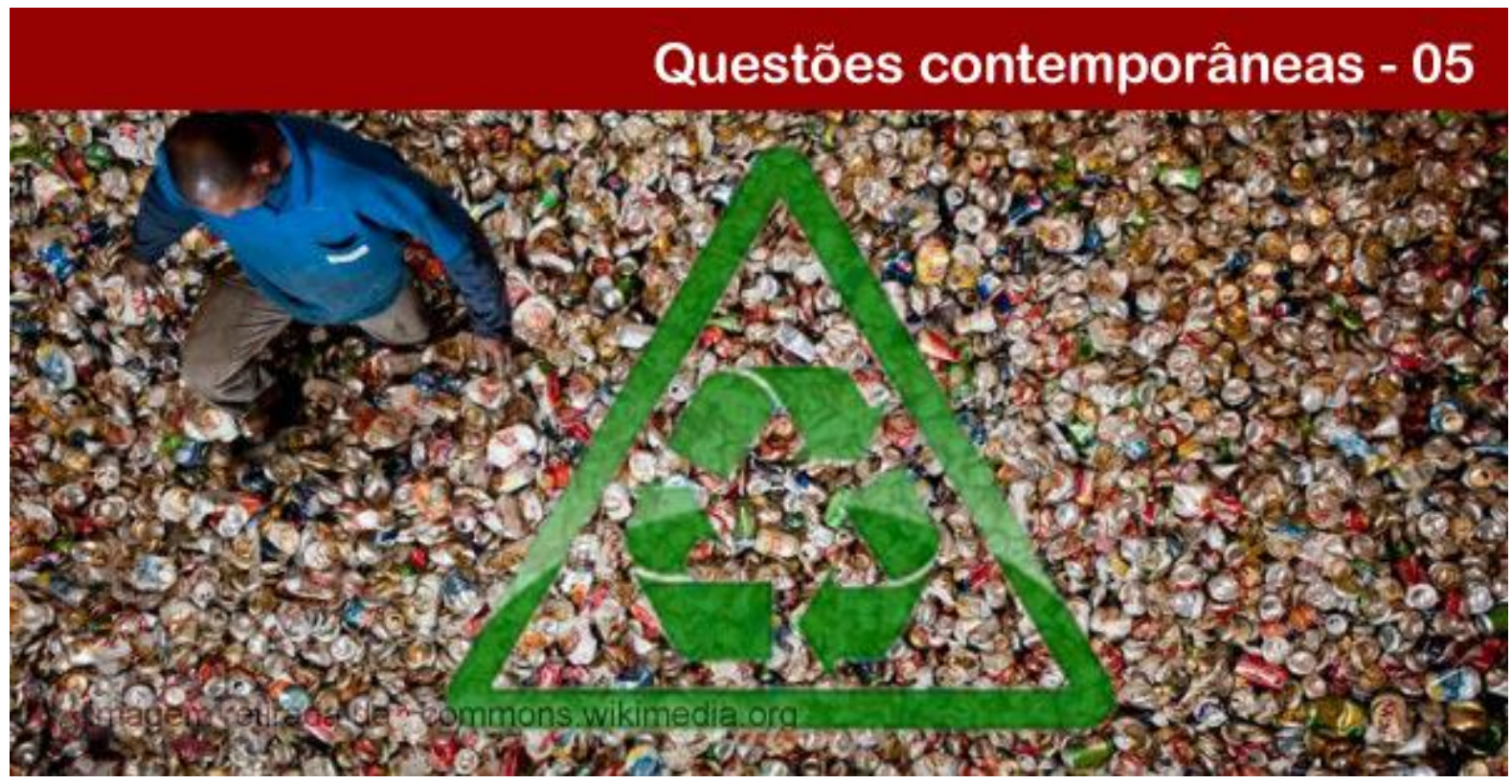

\title{
TECNOLOGIA SOCIAL PARA COLETA E TRANSPORTE DE RESÍDUOS SÓLIDOS: UMA CONTRIBUIÇÃO AO EXERCICIO PROFISSIONAL DE CATADORES DE MATERIAIS RECICLÁVEIS
}

\author{
Lilian Arruda Ribeiro \\ Doutoranda em Desenvolvimento e Meio Ambiente-UFPB, Mestre em Ciência e tecnologia Ambiental/UEPB; \\ Especialista em Desenvolvimento e meio ambiente/FURNE-UEPB; Graduada em Ciências Biológicas/UEPB. E- \\ mail: lilianarruda@gmail.com.

\section{Monica Maria Pereira da Silva} \\ Bióloga pela Universidade Estadual da Paraíba. Especialista em Educação Ambiental/UEPB. Mestra em \\ Desenvolvimento e Meio Ambiente pelo PRODEMA/UEPB/UFCG. Doutora em Recursos Naturais/ UFCG. \\ Professora da UEPB/CCBS/DFB-NEEA (Coordenadora do Projeto Financiado pelo CNPq). E-mail: \\ monicaea@terra.com.br.
}

Resumo: No cenário atual é a partir dos catadores de materiais recicláveis que tem início a gestão dos resíduos, o que implica basicamente na separação dos resíduos na fonte geradora, transformando os catadores de materiais recicláveis de simples coadjuvantes para um dos principais atores no processo de gestão. Objetivou-se desenvolver, implementar e avaliar tecnologias que otimizem a coleta e o transporte dos resíduos sólidos domiciliares recolhidos pelos catadores de materiais recicláveis associados à ARENSA (Associação de catadores de materiais recicláveis da comunidade Nossa Senhora Aparecida), Campina Grande-PB. A pesquisa participante e experimental foi realizada de janeiro de 2013 a julho de 2014 , com $100 \%$ dos associados. No primeiro momento foi executado o levantamento das condições das tecnologias utilizadas pelos catadores de materiais recicláveis, para posteriormente, desenvolver, implementar e avaliar as tecnologias, considerando-se o papel que elas representam dentro do conceito de Tecnologia Social e avaliando-se os aspectos ergonômicos a elas associados. Para tal, foram desenvolvidos dois veículos, com formato de paralelogramo, confeccionados em aço tipo metalon, dois pneus de motocicleta e um de levorin para carrinho de mão, tela transpassada, com sistema de frenagem, tipo alavanca, retrovisores, punhos revestidos de polietileno, adesivos refletivos, caixa para kit de higiene. As tecnologias estudadas possibilitaram melhores condições de trabalho, diminuição do esforço físico, redução de impactos negativos sobre a saúde, além de contribuir para o aumento da renda mensal dos catadores de materiais recicláveis associados à ARENSA em 39\% e favorecer o recolhimento de maior

\section{POLÊM!CA | Revista Eletrônica da Uerj}

Rua São Francisco Xavier, 524, $2^{\circ}$ andar - BL D, sl 2025 - Maracanã

Tels.: +55 $212334-0888$ / 0887

http://www.labore.uerj.br/ - laboreuerj@yahoo.com.br 
quantidade de resíduos (aumento de 12\%), contribuindo assim para a valorização desses trabalhadores e com a política nacional de resíduos sólidos.

Palavras-chave: Catadores de material reciclável. Tecnologia social. Ergonomia.

\title{
SOCIAL TECHNOLOGY FOR COLLECTION AND TRANSPORT OF SOLID WASTE; A CONTRIBUTION TO THE EXERCISE OF PROFESSIONAL COLLECTORS OF RECYCLABLE MATERIALS
}

\begin{abstract}
In the present scenario it is from the waste pickers that starts on waste management, which basically involves the separation of waste at the source, turning the collectors of simple adjuncts of recyclable materials a key player in the management process . The objective was to develop, implement and evaluate technologies that optimize the collection and transportation of solid waste collected by waste pickers associated with ARENSA (Association of recyclable material collectors community Nossa Senhora Aparecida), Campina Grande-PB. The participant and experimental research was conducted from January 2013 to July 2014, 100\% of the associates. At first it was performed a survey of the condition of the technologies used by waste pickers, to further develop, implement and evaluate technologies, considering the the role they represent within the concept of Social Technology and evaluating the ergonomic aspects associated with them. To this end, two vehicles were developed with parallelogram-shaped, made of steel grade metalon two motorcycle tires and a Levorin to Barrow, pierced screen with braking system, lever type, mirrors, coated handles polyethylene, reflective stickers, box for hygiene kit. The technologies studied enabled better working conditions, decreased physical stress, reduction of negative impacts on health, and contribute to increasing the monthly income of waste pickers associated with ARENSA by 39\% and to promote the collection of larger amount of waste (increase of 12\%), thus contributing to the recovery of the workers and national policy on solid waste.
\end{abstract}

Keywords: Collectors of recyclable material. Social technology. Ergonomics.

\section{Introdução}

No cenário atual é a partir da separação de materiais recicláveis na fonte geradora que se dá o início do processo de gerenciamento de resíduos, o qual depende, dentre outros, da participação efetiva dos cidadãos e do reconhecimento do trabalho dos catadores, desde que esse seja realizado em condições adequadas e seguras (REFSGAARD; MAGNUSSEN, 2009).

Para o sucesso deste processo é notável a necessidade do desenvolvimento de tecnologias sociais que vêm se consolidando como estratégia oportuna e eficaz de estímulo à adoção de um modelo de desenvolvimento sustentável, sendo essencial aliar o saber popular, conhecimento técnico ou científico, organização social e participação da comunidade, procurando desenvolver soluções facilmente apropriáveis e reaplicáveis. (BRINGHENTI; ZANDONADE; GUNTHER, 2011). É importante destacar que diferem das tecnologias ditas "convencionais", por não serem definidas apenas pelos resultados e impactos que produzem (OLIVEIRA, 2010), mas por compreender, principalmente um modo de fazer e produzir conhecimento, que presta atenção em valores, como a participação e o aprendizado, a disseminação de conhecimento entre as partes envolvidas, a transformação das pessoas e da realidade social.

\section{POLÊM!CA | Revista Eletronica da ver}


O desenvolvimento de projetos voltados ao exercício profissional dos catadores de materiais recicláveis, para ser bem-sucedido, deve então articular ações de natureza técnica, comercial e organizacional, integradas às tecnologias que otimizem o processo de trabalho (ALEXANDER; JOSHUA, 2012).

Em geral, os catadores de materiais recicláveis adaptam objetos para realização da catação, tais como: carrinhos de diversas formas e modelos ou até mesmo com sacos apoiados nas costas, implicando em possíveis problemas decorrentes da má postura, sem dar a devida importância aos padrões ergonômicos. Em termos de funcionalidade, a função prática de equipamentos relacionados à atividade da catação; engloba questões pautadas na ergonomia técnica (resistência e durabilidade do material) e ergonomia física (praticidade, segurança e conforto), logo, para que o desenvolvimento de tecnologias direcionadas ao público do setor da catação seja bem sucedido, deve ser considerado o contexto socioeconômico e cultural, expressando as necessidades, sonhos, desejos, valores e expectativas do grupo em estudo.

Segundo Peredo e Mcclean (2011), poucas são as tecnologias existentes no mercado atuais desenvolvidas para atender as necessidades dos catadores de materiais recicláveis, além disso, não existe uma maior preocupação com relação aos aspectos ergonômicos dessas tecnologias.

A realização de projetos dessa natureza visa o desenvolvimento de uma infraestrutura técnica e da organização dos processos de produção nas etapas de coleta, triagem, transporte e comercialização, que deve conter elementos básicos, a saber: a) galpão equipado para a atividade de triagem, b) sistemas de veículos de coleta funcionais, c) sistemas de coleta seletiva otimizados, envolvendo mobilização social, organização da coleta e logística. Esses elementos, por sua vez, motivaram os questionamentos que alicerçaram o presente trabalho: Tecnologias para coleta e transporte desenvolvidas a partir do olhar dos catadores de materiais recicláveis favorecem a redução de esforço físico, recolhimento de maior quantidade de resíduos e aumento da renda mensal?

O objetivo principal deste trabalho foi desenvolver, implementar e avaliar tecnologias que otimizem a coleta e o transporte dos resíduos sólidos recolhidos pelos catadores de materiais recicláveis associados à ARENSA (Associação de catadores (as) de materiais recicláveis da comunidade Nossa Senhora Aparecida), localizada em Campina Grande-PB e

\section{POLÊM!CA | Revista Eletronica da Ueij}


proporcionem a amenização de esforço físico, o recolhimento de maior quantidade de resíduos e aumento da renda mensal.

\section{Metodologia}

O presente trabalho trata de uma pesquisa participante (THIOLLENT, 2008) e experimental (MARCONI; LAKATOS, 1999), realizada de Janeiro de 2013 a Julho de 2014, com quatorze (100\%) catadores de materiais recicláveis associados à ARENSA (Associação de Catadores de Materiais Recicláveis da Comunidade Nossa Senhora Aparecida), em Campina Grande-PB.

Para análise ergonômica foi utilizado o método do design macroergonômico (DM) proposto por Fogliatto e Guimarães (1999), o qual faz uma abordagem sociotécnica porque lida com quatro subsistemas: o tecnológico, o pessoal, o do trabalho e o do ambiente externo, ou seja, adota simultaneamente uma abordagem estratégica, participativa e foca no processo.

A comunidade Nossa Senhora Aparecida foi escolhida, principalmente, em decorrência de um projeto anteriormente realizado nessa localidade (SILVA, 2009) e, a partir desse projeto, foi fundada em 2010 a ARENSA, público-alvo do presente estudo, tendo sido objeto de estudo de diversos trabalhos (SILVA et al., 2012; RIBEIRO et al., 2011).

A coleta de dados foi executada em quatro etapas, as quais permitiram observar a dinâmica de trabalho dos catadores de materiais recicláveis e o desenvolvimento e investigação das tecnologias para a coleta e o transporte dos materiais recolhidos.

$\mathrm{Na}$ primeira etapa foi realizado o levantamento das condições das tecnologias utilizadas pelos catadores de materiais recicláveis associados à ARENSA, através de observação direta, entrevistas semiestruturada e registros fotográficos. As principais variáveis investigadas foram: condições de trabalho; tecnologias adotadas para o transporte; acondicionamento; triagem e armazenamento.

Em relação aos transportes já adotados pelos catadores de materiais recicláveis da ARENSA foram avaliadas as seguintes variáveis: capacidade volumétrica, durabilidade, facilidade de manuseio ou operação, custo de construção, esforço físico, vulnerabilidade a acidentes.

No segundo momento foi investigada e desenvolvida a tecnologia para coleta e transporte de resíduos, observando-se os princípios da tecnologia social. Foram empregados

\section{POLÊM!CA | Revista Eletronica da veri}


ajustes às tecnologias existentes, considerando-se as necessidades apontadas pelos catadores de materiais recicláveis. Nessa etapa os dados foram coletados a partir de observação direta e acompanhamento das atividades exercidas pelos catadores de materiais recicláveis. Esse procedimento aconteceu em dois ciclos e cada ciclo foi composto por três acompanhamentos.

Para o desenvolvimento da tecnologia de coleta e transporte foi construído um veículo com carroceria gradeada e móvel e com pneus que promovam maior agilidade, buscando-se reduzir o esforço físico dos catadores de materiais recicláveis. Esse veículo foi denominado de T4 (Transporte 4) para se diferenciar dos demais carrinhos já usados pelos catadores de materiais recicláveis $(\mathrm{T} 1, \mathrm{~T} 2$ e T3).

A terceira etapa constou da construção e avaliação de outro veículo (T5). Esse foi confeccionado a partir de acompanhamentos das atividades das indicações de ajustes ao T4, apontadas pelos catadores de materiais recicláveis. Para a avaliação foi seguido o procedimento descrito na segunda etapa.

$\mathrm{Na}$ quarta etapa foram identificados os impactos positivos proporcionados a partir do desenvolvimento das tecnologias de coleta e transporte. Nessa etapa os dados foram coletados através de observação participante, aplicação de entrevista semiestruturada e acompanhamento das atividades dos catadores de materiais recicláveis, cinco meses antes e cinco meses após a entrega das tecnologias de transporte, para análise de requisitos como renda, quantidade de material coletado, esforço físico.

Os dados foram analisados de forma quantitativa e qualitativa, utilizando-se da triangulação que segundo Thiollent (2008) consiste em quantificar, qualificar e descrever os dados obtidos. Os dados quantitativos foram distribuídos em categorias e posteriormente, avaliados por meio de métodos estatísticos simples, como porcentagem.

\section{Resultados e discussão}

Diagnóstico das tecnologias utilizadas, para coleta e transporte de resíduos sólidos, pelos catadores de materiais recicláveis associados à ARENSA

Para realização da coleta dos resíduos sólidos, os catadores de materiais recicláveis dispunham de três transportes:

\section{POLÊM!CA | Revista Eletronica da veri}


O transporte 1 (T1), chamado pelos próprios catadores de carrinho de geladeira, pelo fato do mesmo ser confeccionado com o caixão da geladeira descartada, além de braços ou pegas de madeira, em geral, putrificadas, resultantes da ação de agentes físicos, químicos e biológicos, estruturas de ferro e pneus de bicicleta, que furam ou estouram com facilidade.

O caixão de geladeira utilizado como vão do T1, não apresenta local para escoar a água, o que dificulta a higienização do mesmo e acelera o processo de oxidação. A lataria também apresenta problemas, como amassões e arranhões provenientes da necessidade de “jogar” o veículo para descarregar.

O T1 encontrava-se em estado de oxidação, tendo em vista que o mesmo foi confeccionado com ferro, e estava sujeito a sol e chuva; condições favoráveis a esse processo, e oferecendo riscos à saúde dos que manuseiam o veículo. Tais características resultam em inadequações e falta de durabilidade dos veículos, diminuindo a remuneração e provocando problemas de saúde, tais como: dores musculares e esqueléticas, sendo a região lombar a mais afetada; cansaço físico; dores de cabeça; erupções cutâneas; indigestão; gastrite; insônia; dificuldade em se concentrar; oscilação de humor (ALENCAR et al., 2009).

O transporte 2 (T2), chamado pelos associados da ARENSA de carrinho preto por ter essa cor em sua estrutura, foi confeccionado com aço tipo metalon de ferro 20x20 mm e arame liso ovalado de $3 \mathrm{~mm}$, com dois pneus de motocicletas chumbados com solda, assim como toda a estrutura do mesmo.

O transporte 3 (T3), ou carrinho azul, por ter sido pintado nessa cor, foi confeccionado com aço tipo metalon de alumínio 20x20, arame transpassado $3 \mathrm{~mm}$ e duas rodas de motocicleta.

Os transportes já existentes foram projetados sem considerar os critérios de: dimensão; forma; material; segurança e princípios ergonômicos, visto que apresentam como principais limitações: baixa capacidade para armazenar resíduos durante a coleta; o material utilizado na confecção apresenta curta durabilidade; requer grande esforço físico para o deslocamento, somado aos problemas para domínio do veículo em ruas de relevo íngreme.

A partir dos veículos T1, T2 e T3, os catadores de materiais recicláveis apontaram mudanças que foram consideradas e aplicadas na confecção do veículo 4 (T4). Dentre as recomendações destacam-se: uso de material que ofereça maior durabilidade; menor peso; design confortável a estatura corporal do grupo em estudo; rodas que amorteçam os desníveis

\section{POLÊM!CA | Revista Eletronica da Uerj}


encontrados no percurso; estrutura para auxiliar na frenagem; compartimento para guardar objetos pessoais e uma estrutura que os ajudem na hora de descarregar o veiculo, para evitar que o mesmo necessite ser "jogado" para retirar os resíduos, ou que o catador de material reciclável entre no veículo para realizar o processo de descarga.

\section{Desenvolvimento e implementação de tecnologia para o transporte de resíduos sólidos}

Tendo como base os resultados dos estudos dos veículos já existentes na ARENSA, constatou-se que estes apresentavam dimensionamentos sem justificativa, mas segundo os catadores de materiais recicláveis, o transporte não pode ter tamanho muito pequeno, para evitar deslocamentos ao local de descarga, nem muito grande, para não aumentar o peso, nem dificultar a passagem nas ruas.

As indicações dos catadores de materiais recicláveis estão em consonância com as de Mendonça, Lobo e Magen (2011). Esses autores afirmam que é interessante que veículos de tração humana tenham a largura inferior ao de um carro de passeio popular (aproximadamente 1,7 m), para que o transporte dos catadores de materiais recicláveis possa transitar em vias públicas com maior agilidade, sem prejudicar a mobilidade urbana. Sabe-se que relação entre a largura e altura influencia no tombamento do carrinho em situações de curvas, devido ao centro de gravidade, não podendo ser muito reduzida.

A redução do peso dos veículos é algo almejado por todos que trabalham na catação, porém, para os catadores de materiais recicláveis, um carrinho leve significa fácil de puxar, ou seja, com um sistema de rolamento eficaz. Nesse sentido, foi projetado o novo veículo, o T4 (também chamado pelos catadores de materiais recicláveis da ARENSA de "carrinho das Malvinas", pois é utilizado para coleta realizada no bairro de mesmo nome), o uso de pneu de carro, pois apresenta diâmetro e resistência maiores, uma vez que o de bicicleta, usado anteriormente, não foi viável, por ser muito fino para o peso que é submetido. O pneu de motocicleta pode quebrar seus raios, o que requer uma manutenção, mas, tomando-se por base o custo e o peso do transporte, foi sugerido continuar o uso desse pneu devido a sua durabilidade e custo. Destaca-se que pneus em borracha aumentam a aderência em contato com o solo, proporcionando maior segurança e estabilidade, como comprovado in locu através do acompanhamento da catação.

\section{POLÊM!CA | Revista Eletronica da Ueij}


A função essencial do pneu é interagir com o solo produzindo forças necessárias para o movimento do veículo. Conforme Holmberg, Andersson, Erdemir (2011), a geração de forças laterais controla a direção do veículo, e a aceleração lateral controla o veículo em curvas.

De acordo com Lagarinhos (2011), a primeira função de um pneu é funcionar como um suporte elástico para as rodas, reduzindo a força necessária para a tração do veículo, proporcionando movimentos mais suaves e menos rumorosos. Por ser mais flexível, o pneu de motocicleta proporciona maior conforto e segurança durante a rodagem, o pneu tem maior superfície de contato com o solo, o que aumenta a capacidade de tração, ou seja, melhor manuseio e estabilidade.

Como o veículo carrega materiais com volume e pesos variados, a estrutura deve ser de qualidade, concebida com boa soldagem e material resistente, o que implica num possível aumento do peso final do transporte em estudo, sendo necessário se discutir a quantidade de rodas a ser utilizada, uma vez que esse parâmetro influencia na sua estabilidade. Esse foi outro ponto apontado pelos catadores de materiais recicláveis, uma vez que os transportes usados na ARENSA possuem duas rodas, o que os tornam financeiramente mais viáveis, no entanto, não operam de forma estável. Na tentativa de superar tal limitação, optou-se por três rodas.

Com relação ao item estabilidade da carga sobre o veículo, Maccarini et al. (2014) mencionam que esse item pode ser prejudicado, devido as características dos resíduos coletados (peso, volume e dimensões). Outra justificativa é a acomodação dos resíduos de acordo com a ordem que são recolhidos, dificultando a distribuição uniforme no transporte.

A opção pelo uso de três rodas foi feita porque auxiliam na distribuição do peso, e na estabilidade do transporte.

Seguindo o raciocínio de Broberg (2010), no intuito de facilitar as curvas, a terceira roda é móvel, e colocada na parte dianteira, por dois motivos: a) Com a roda na frente, o braço do carrinho torna-se maior e, consequentemente, a força será menor, favorecendo o trabalho dos catadores de materiais recicláveis; b) Com a roda na parte traseira do carrinho, no caso de curvas, o carrinho poderia colidir com algum obstáculo.

Com relação ao armazenamento dos resíduos, o compartimento de carga deve guardar de forma prática todos os resíduos coletados. Inicialmente, foi projetada a divisão desse local

\section{POLÊM!CA | Revista Eletronica da Uerj}


em pequenos vãos, para facilitar o processo de triagem, entretanto, a geometria e o tipo dos materiais coletados possuem variação, o que o tornaria inviável. Então, adotou-se um vão único, gradeado e com armação tubular.

O compartimento de carga deve permitir a entrada e saída dos materiais com facilidade, e durante o percurso de coleta dos resíduos não poderá deixar nenhum material coletado cair ao longo do caminho, o que implicaria em perda de tempo e dinheiro, além de sujar o meio ambiente.

Para a confecção do compartimento, foram utilizadas cantoneiras de aço tipo metalon 30x30 mm e uma tela transpassada de arame de $3,2 \mathrm{~mm}$, revestindo toda a extensão do transporte. A utilização desse tipo de material justifica-se por ser resistente, de fácil manutenção e pela leveza, atendendo às prerrogativas indicadas pelos catadores de materiais recicláveis.

Ainda considerando o compartimento de carga, nas laterais foram colocadas aberturas para funcionar como extensores, facilitando a acomodação dos resíduos ao longo da coleta. Quando o carrinho atinge a capacidade máxima, essa abertura é fechada e o acondicionamento é feito apenas pela parte superior, aumentando o esforço físico.

A parte traseira do carrinho é toda aberta no sentido de baixo para cima, facilitando o processo de descarga dos resíduos, uma vez que o próprio peso do material o desloca para fora. A essa porta foi adicionado um dispositivo simples de travamento, impedindo que ela se abra durante o deslocamento. Tal medida foi adotada, pois, atualmente os resíduos são descarregados, "jogando-se” o carrinho para que o mesmo vire e os resíduos caiam no solo, o que reduz a vida útil do transporte.

As aberturas laterais encaixam-se perfeitamente na mesa de triagem, para que quando a porta seja aberta, o resíduo fique no local de triagem, resultando em ganho de tempo e benefícios posturais.

Quando o nível dos resíduos fica abaixo da abertura lateral, é destravada a porta traseira, para retirar o restante do material a ser triado, não necessitando "jogar" o veículo para descarregá-lo, aumentando-se a vida útil do mesmo.

$\mathrm{Na}$ tentativa de contribuir para a segurança, foram instaladas faixas refletivas nos carrinhos, de acordo com a NBR 14644 (ABNT, 2001), e espelhos retrovisores de motocicletas, para que os catadores de materiais recicláveis sejam melhores visualizados

\section{POLÊM!CA | Revista Eletronica da Uerj}


pelos motoristas e consigam enxergar o que acontece à sua traseira, facilitando principalmente manobras de curvas.

De acordo com o item 3.1.2 da NBR 7195/1995 (ABNT, 1995), o transporte deveria ter sido pintado na cor laranja, indicada para demonstrar perigo, mas os associados da ARENSA não concordaram com essa cor, uma vez que a cor azul é característica da organização e os ajudam a serem reconhecidos nas ruas, e como este transporte tem por base o princípio da tecnologia social, atendeu-se às indicações dos associados.

Em síntese, o veículo T4 apresentou as seguintes características: tração humana; compartimento único; de formato retangular para armazenamento dos resíduos coletados; três rodas, sendo as duas traseiras fixas e de motocicletas com rolamento e a roda dianteira de rodízio de tipo nylon oito polegadas móvel; braços ligeiramente curvados; capacidade para $180 \mathrm{~kg}$; com duas aberturas laterais e uma traseira; faixas refletivas e espelhos retrovisores. Os critérios ponderados foram: baixo custo; leveza; praticidade; simplicidade; fácil manutenção; alta durabilidade e segurança, como também foram observados os princípios da ergonomia.

A partir do acompanhamento do exercício profissional dos catadores de materiais recicláveis, foram avaliados os ajustes sugeridos para o veículo T4, resultando na confecção do veículo denominado T5 (chamado pelos trabalhadores da ARENSA de carrinho da ARENSA, por ter sido aquele que mais agradou ao grupo em estudo).

O transporte (T5) foi confeccionado com aço tipo metalon 20x20mm, tela transpassada de arame de 1,2 $\mathrm{mm}$ toda soldada, pneu dianteiro Levorin para carro de mão, freio de cabo de aço de embreagem. A tela transpassada de contenção é responsável por suportar toda a força exercida pelos resíduos coletados. É composta por quadrados relativamente pequenos, evitando a queda de pequenos objetos durante o percurso. O T5 possui uma porta traseira com duas dobradiças na parte superior para permitir o movimento de abrir e fechar a porta e duas correntes para segurar essa porta quando a mesma estiver aberta de forma que os materiais coletados possam ser retirados sem oferecer perigo ao trabalhador. A porta é travada através de dois trincos soldados junta a estrutura do transporte e da porta.

A quantidade de rodas (três) e o tipo (motocicleta e de carrinho de mão) foram escolhidos para conceder aos usuários boa ergonomia durante o transporte da carga, reduzindo

\section{POLÊM!CA | Revista Eletronica da Ueij}


impactos negativos como a irregularidade dos terrenos e sobre a saúde do trabalhador, decorrente principalmente do peso excessivo transportado diariamente.

Segundo Berenguel (2011), essas rodas escolhidas são as mais indicadas para o tipo de trabalho realizado pelo transporte em estudo, uma vez que suportam a carga diária de peso sem necessitar de manutenção e/ou troca com frequência, o que a torna uma opção de baixo custo.

Para segurança, foi instalado um sistema de frenagem realizada por freio do tipo alavanca, por ter um custo reduzido e fácil manuseio. Os retrovisores que auxiliam na visualização na hora de realizar manobras, principalmente quando o transporte está cheio, sofreram alterações na altura, adaptando-se melhor à estatura dos associados que manuseiam o veículo.

A altura das pegas (local onde os catadores seguram o transporte durante a coleta dos materiais recicláveis) é regulada por um pino e uma barra móvel, facilitando-a adequação de entrada e saída do usuário de acordo com sua estatura, evitando o uso desnecessário das articulações do joelho e coluna dos catadores de materiais recicláveis.

As pegas, revestidas de polietileno, apresentam formato quadrangular, tendo em vista estudos realizados por Medola et al (2014): o tubo metálico circular não oferece suporte estável e confortável para toda a superfície da mão, como resultado, os usuários necessitam exercer maior força de preensão nas regiões de contato (Figura 1).

Figura - 1: A-Retrovisores que auxiliam na visualização do entorno; B-Pegas revestidas de polietileno oferecendo maior conforto e segurança; C- Freio tipo alavanca; D-Faixas refletivas que auxiliam a visualização dos catadores de materiais recicláveis nas ruas.

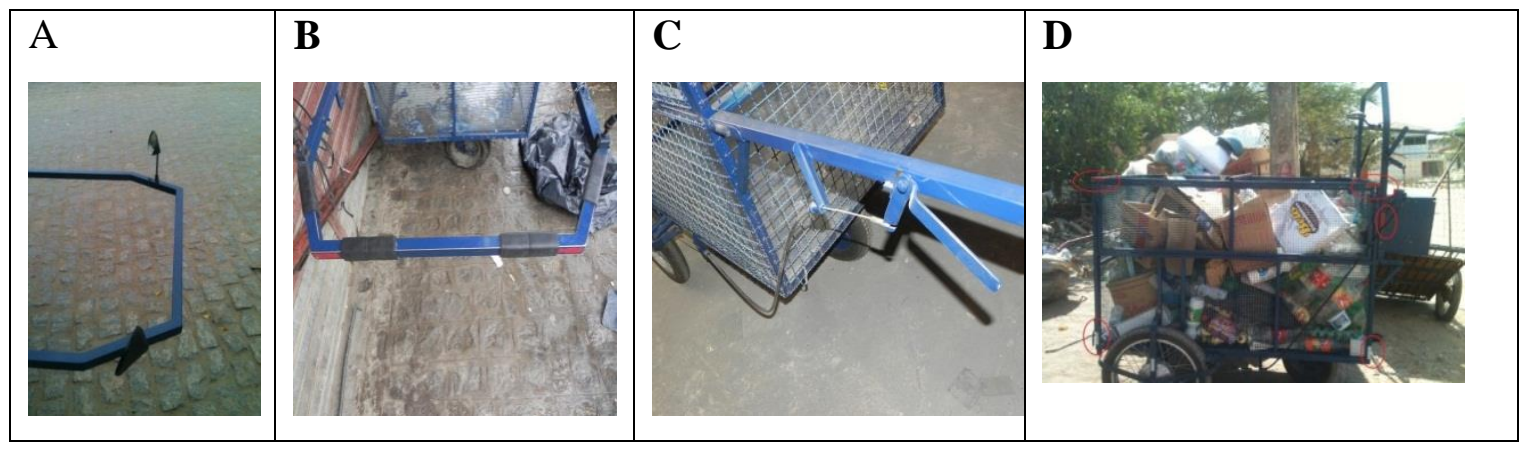

Considerando-se o conforto, higiene e melhores condições de trabalho para os catadores de materiais recicláveis ao longo de sua jornada diária de trabalho, foi instalada uma 
caixa de acessórios para guardar objetos pessoais, produtos para higiene pessoal ou até mesmo alimentação. Essa caixa é removível, facilitando a higienização da mesma.

O veículo T5 apresentou, quando seco, peso de $86 \mathrm{~kg}$, com capacidade para transportar $180 \mathrm{~kg}$ de uma só vez, resultando num acréscimo de $12 \%$ e $39 \%$ para a quantidade coletada e a renda mensal, respectivamente, e menor demanda de esforço físico para conduzi-lo, o qual foi reduzido devido às três rodas utilizadas, sendo as duas traseiras de motocicleta e a dianteira de Levorin para carrinho de mão, bem como pela sua excelente durabilidade. Além disso, o T5 foi produzido com pegas de aço móvel com design em polímero, freios tipo alavanca e com as seguintes dimensões: 1,4 m de largura; 2,4 m de comprimento e 1,5 m de altura.

Segundo relatos dos trabalhadores de materiais recicláveis associados à ARENSA, com tais tecnologias propostas, houve melhora na qualidade do trabalho, tais como: diminuição das dores nos membros superiores e inferiores; facilidade de realizar manobras; segurança em parar ou descer com veiculo em ruas enladeiradas; comodidade ao colocar e retirar resíduos no transporte e coleta de maior quantidade de resíduos em menor espaço de tempo (até $180 \mathrm{~kg}$ ).

Análise das tecnologias desenvolvidas para o transporte dos resíduos sólidos

As tecnologias desenvolvidas para o transporte dos resíduos apresentam características que favorecem o exercício profissional dos catadores de materiais recicláveis (Tabela 1), no entanto, o T5 atendeu com maior eficiência as necessidades do grupo estudado, especialmente, por resultar de ampla investigação que motivou a correção de possíveis fatores limitantes, no que diz respeito ao esforço físico desprendido, baixo custo, facilidade de manutenção e operação.

Entende-se por manuseio satisfatório o fato do transporte ter mais utensílios que auxiliem na qualidade do trabalho, não apresentando dificuldades para usá-los, porém, ele não agradou aos $100 \%$ dos catadores de materiais recicláveis que os utilizam. Por sua vez, o manuseio excelente é aquele que foi aprovado por todos os catadores de materiais recicláveis, eximindo-se de ajustes. Os itens manutenção e durabilidade foram baseados no mesmo raciocínio.

\section{POLÊM!CA | Revista Eletronica da Uerj}


O valor total das tecnologias foi obtido após a definição do modelo proposto e da escolha dos materiais a serem utilizados e orçados através de uma pesquisa de mercado. Para realizar a seleção dos materiais, consideraram-se os seguintes aspectos: propriedades mecânicas e físicas; influências com o meio ambiente; processo de fabricação; custos; acabamentos; redução de peso, dentre outros.

Tabela - 1: Comparação entre as tecnologias de coleta e tecnologias empregadas na ARENSA e aquelas desenvolvidas. Campina Grande, julho de 2014.

\begin{tabular}{|c|c|c|c|c|c|}
\hline Características & T1 & T2 & T3 & T4 & T5 \\
\hline Peso seco (kg) & 46 & 100 & 100 & 120 & 86 \\
\hline $\begin{array}{l}\text { Capacidade de } \\
\text { carga }(\mathrm{kg})\end{array}$ & 42 & 100 & 120 & 180 & 180 \\
\hline Durabilidade $^{1}$ & 3 & 4 & 5 & 9 & 10 \\
\hline Manuseio $^{1}$ & 5 & 6 & 6 & 8 & 9 \\
\hline Freios & Ausente & Ausente & Ausente & Ausente & Presente \\
\hline Pegas & $\begin{array}{l}\text { Madeira } \\
\text { fixa }\end{array}$ & $\begin{array}{l}\text { Aço fixa reta e } \\
\text { fechada }\end{array}$ & $\begin{array}{c}\text { Aço fixa reta e } \\
\text { aberta }\end{array}$ & Aço fixa com design & $\begin{array}{l}\text { Aço móvel com } \\
\text { design e polímero }\end{array}$ \\
\hline Rodas & Bicicleta & Motocicleta & Motocicleta & $\begin{array}{l}\text { Rodízio de nylon e } \\
\text { motocicleta }\end{array}$ & $\begin{array}{c}\text { Levorin } 4.10 / 3.50-8 \mathrm{e} \\
\text { motocicleta }\end{array}$ \\
\hline Quantidade de rodas & 2 & 2 & 2 & 3 & 3 \\
\hline $\begin{array}{l}\text { Dimensões (m) } \\
\text { LxCxA }\end{array}$ & $0,6 \times 1,2 \times 1,3$ & $0,9 \times 1,5 \times 1,3$ & $0,6 \times 1,5 \times 1,5$ & $1,4 \times 2,4 \times 1,5$ & $1,4 \times 2,4 \times 1,5$ \\
\hline Custo (R\$) & - & 450,00 & 620,00 & $1.600,00$ & $2.000,00$ \\
\hline
\end{tabular}

${ }^{1}$. Notas de 0 a 10 aplicadas pelos associados da ARENSA.

T1 - Carrinho de Geladeira; T2 - Carrinho Preto; T3- Carrinho Azul; T4-carrinho das Malvinas; T5-Carrinho da ARENSA.

Os valores referentes aos veículos T4 e T5 podem ser considerados altos, tendo em vista o público-alvo, todavia, quando produzidos em grande escala, tende a baixar consideravelmente. Destaca-se que são adicionados ao valor investido nos transportes, os custos com a sua projeção.

Para Maccarini et al. (2014), o valor das inovações que trazem bem-estar para as pessoas não pode ser materializado somente em números e equações contábeis, uma vez que o valor dessas obras será a melhoria na qualidade de vida das pessoas. 
Na busca para minimizar os gastos na fabricação dessa tecnologia, foi sugerido utilizar o transporte dos catadores de materiais recicláveis como "propaganda móvel”, uma vez que os catadores de materiais recicláveis percorrem diariamente grandes distâncias $(20 \mathrm{~km} / \mathrm{dia})$ e localidades diferentes. Para isto, foi implantado um banner de lona na parte traseira e nas laterais do transporte para que possa ser alugado e o valor retorne como renda extra para a associação.

Para avaliação qualitativa dos itens relativos às tecnologias de coleta e transportes desenvolvidas e aplicadas foram atribuídos os seguintes conceitos: Excelente (E), Bom (B), Ruim (R) e Ausentes (A), de acordo com concepção dos próprios usuários e associados da ARENSA (Quadro 1).

De acordo com os dados expostos a Tabela 1 e Quadro 1, verifica-se que o T1(Figura 2), o primeiro a ser usado pelos catadores de materiais recicláveis associados à ARENSA, não apresentou nenhum benefício, comparando-se aos demais, uma vez que seu peso é maior do que sua capacidade de carga, resultando num maior desgaste físico por parte dos trabalhadores que o utilizam e pelo pouco material coletado (42 kg/percurso), afetando a renda, além de sua durabilidade ser baixa.

Quadro - 1: Avaliação qualitativa das tecnologias de coleta e transporte pelos associados da ARENSA. Campina Grande-PB, 2014

\begin{tabular}{|cccccc|}
\hline & \multicolumn{4}{c|}{ Avaliação dos Transportes } \\
Características & T1 & T2 & T3 & T4 & T5 \\
\hline Peso seco & $\mathrm{E}$ & $\mathrm{R}$ & $\mathrm{R}$ & $\mathrm{R}$ & $\mathrm{E}$ \\
Capacidade de carga & $\mathrm{R}$ & $\mathrm{R}$ & $\mathrm{B}$ & $\mathrm{E}$ & $\mathrm{E}$ \\
Durabilidade & $\mathrm{R}$ & $\mathrm{R}$ & $\mathrm{R}$ & $\mathrm{E}$ & $\mathrm{E}$ \\
Manuseio & $\mathrm{R}$ & $\mathrm{R}$ & $\mathrm{B}$ & $\mathrm{B}$ & $\mathrm{E}$ \\
Freios & $\mathrm{A}$ & $\mathrm{A}$ & $\mathrm{A}$ & $\mathrm{A}$ & $\mathrm{E}$ \\
Pegas & $\mathrm{R}$ & $\mathrm{R}$ & $\mathrm{R}$ & $\mathrm{R}$ & $\mathrm{E}$ \\
Rodas & $\mathrm{R}$ & $\mathrm{R}$ & $\mathrm{B}$ & $\mathrm{B}$ & $\mathrm{E}$ \\
Quantidade de rodas & $\mathrm{R}$ & $\mathrm{R}$ & $\mathrm{R}$ & $\mathrm{E}$ & $\mathrm{E}$ \\
Dimensões & $\mathrm{R}$ & $\mathrm{R}$ & $\mathrm{R}$ & $\mathrm{E}$ & $\mathrm{E}$ \\
\hline
\end{tabular}

A-Ausentes; R-Ruim; B-Bom; E-Excelente

Com exceção do quesito peso seco, o T1 não apresentou características que auxiliem na diminuição da fadiga física, sendo considerado pelos associados como manuseio ruim. $\mathrm{E}$ com a frequente exposição à chuva e ao sol durante o período de coleta, as partes do transporte confeccionado com ferro e madeira, oxidam e apodrecem e o pneu de bicicleta não ameniza o desgaste físico por ter um diâmetro reduzido.

\section{POLÊM!CA | Revista Eletronica da Ueij}


O transporte T2 (Figura 2) apresentou grande evolução, mesmo que seu peso também tenha sido alto, a sua capacidade de carga também foi aumentada (para $100 \mathrm{~kg}$ ), sendo essa uma das características que mais agradou aos catadores de materiais recicláveis. O pneu utilizado de motocicleta é mais resistente. Sua durabilidade não foi considerada boa (entendese por durabilidade a vida útil do veículo, o tempo utilizado até a primeira manutenção, a periodicidade da manutenção, a necessidade de troca de pneus, a qualidade/ resistência do material utilizado na fabricação do vão). O T2, apenas com dois meses de uso, requereu reparos em sua estrutura, pois o material usado para fazer o gradeamento não foi forte o suficiente para aguentar a pressão que os materiais coletados fazem nas laterais do carrinho quando ele está cheio.

Com relação ao manuseio, os catadores de materiais recicláveis o avaliaram como satisfatório e ao mesmo tempo apontaram um ponto negativo: a abertura na parte traseira e posterior. Este detalhe por um lado é bom, uma vez que diminui o esforço dos catadores de materiais recicláveis para "jogar" o material coletado dentro do carrinho, e por outro, ruim, pois quando o carrinho está com sua capacidade máxima, é necessário colocar apoios, que em geral, são de papelão, a fim de evitar o derramamento de material ao longo do percurso.

Outra característica apontada como negativa pelo público estudado foi o "braço" ou pega, local onde os catadores de materiais recicláveis empurram ou puxam o veículo, pois ele é totalmente reto, o que acarreta dores musculares.

O T3 (Figura 2) apresentou modificações solicitadas pelos catadores de materiais recicláveis associados à ARENSA, tendo em vista os transportes já existentes no local. O peso não foi alterado em relação ao protótipo anterior, mas a sua capacidade de carga foi aumentada (para $120 \mathrm{~kg}$ ), o que pode ser considerado como impacto positivo por resultar em menor esforço físico e aumento de renda.

Figura - 2: Imagens do veículo T1, T2 e T3 usado pela ARENSA. Campina Grande -PB, 2014.

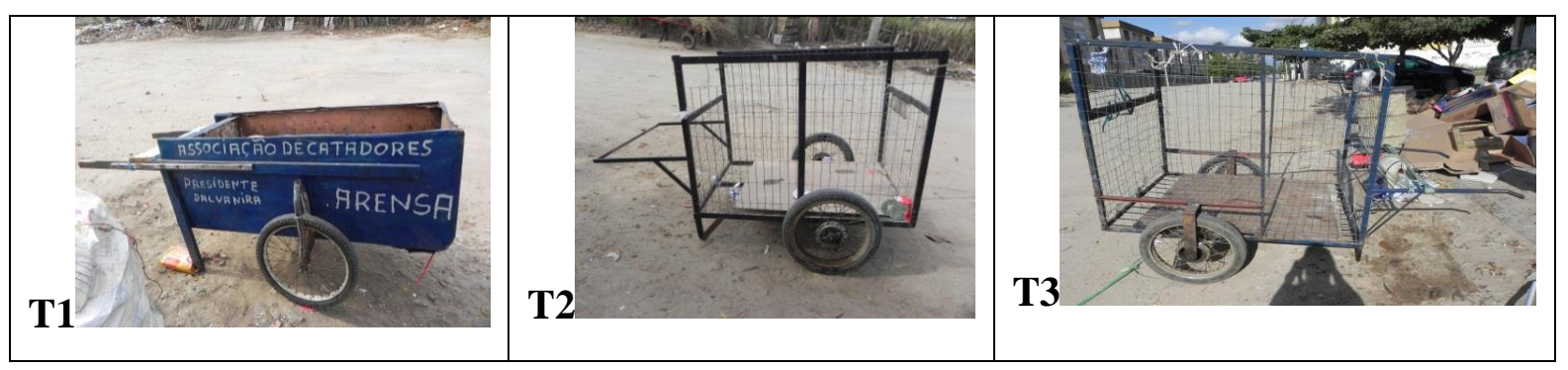


A durabilidade esperada desses transportes ainda não foi alcançada. Segundo Castilhos Jr. et al (2013), o tempo de uso dos veículos de tração humana varia de um a três anos, com pouca ou nenhuma necessidade de reparos, apenas a manutenção preventiva.

O braço do carrinho T3 é aberto, possui uma inclinação para tentar minimizar o esforço físico nos membros superiores, porém, ainda persistiu limitação, tendo em vista que os braços ficam muito afastados, culminando em dores musculares no final da jornada de trabalho diário. Na tentativa de resolver o problema da abertura frontal e traseira, foi colocada uma "janela" que quando o carrinho está seco, usa-se aberta, e quando o carrinho está cheio, fecha-se para evitar perda de material.

O veículo T3 apresentou vários pontos positivos relacionados ao manuseio quando comparado aos que foram usados anteriormente pelos trabalhadores associados à ARENSA (SILVA et al, 2013), sendo esse tomado como referência que surgiram algumas observações importantes para os outros veículos: o braço do T4 e T5 não poderia ser muito grande, por representar um risco aos catadores de materiais recicláveis, pois em caso do carrinho “tombar" para trás, o apoio frontal das mãos poderia atingir o queixo do catador de materiais recicláveis.

Segundo Dul e Weerdmester (2004) os carrinhos devem ter os braços em forma de barra, para que os catadores de materiais recicláveis utilizem as duas mãos para transmitir a força necessária para mover o carrinho, mas é fundamental haver uma leve inclinação para descanso dos braços, além de possuir uma proteção na área de pega para que as mãos não fiquem em contato direto com o metal, causando desconforto, ou mesmo escorregue com o suor ou chuva. Por conseguinte, o braço do novo carrinho (T5) deveria ser parcialmente revestido em tubo emborrachado de material NBR, similar ao empregado em punhos de bicicleta. E ainda ser fixado ao compartimento de carga, que fica para trás. Quando o carrinho estiver com sua capacidade máxima, o condutor não perde sua visibilidade, aumentando a sua segurança e a de todos que trafegam próximo.

Em síntese o T4 apresentou as seguintes características: tração humana; com um compartimento único; de formato retangular, confeccionado com aço carbono 30x30mm, transpassado de arame 3,2mm, medindo 1,4m de largura, 2,4m de comprimento e 1,5m de altura, pesando $120 \mathrm{~kg}$ quando seco; três rodas, as duas traseiras fixas e de motocicletas com

\section{POLÊM!CA | Revista Eletronica da Ueij}


rolamento e a roda dianteira de rodízio de nylon, oito polegadas móvel; braços ligeiramente curvados; capacidade para $180 \mathrm{~kg}$; com duas aberturas laterais e uma traseira; faixa refletivas e espelhos retrovisores. Os critérios ponderados foram: custo, peso, praticidade, simplicidade, manutenção, ergonomia, durabilidade e segurança.

Este modelo foi confeccionado e posteriormente testado pelos catadores de materiais recicláveis associados à ARENSA e durante três meses foi avaliada a sua eficiência.

A partir do acompanhamento deste novo carrinho e considerando a opinião e experiência dos trabalhadores desta área em estudo, foram sugeridas modificações para confecção do transporte 5 , o T5.

O veículo T5 apresentou como impactos positivos: a redução no seu peso total para $86 \mathrm{~kg}$ quando seco, e alta capacidade de carga(180kg); facilidade no manuseio; sistema de frenagem; três rodas pneumáticas que oferecem maior estabilidade e amortecimento das irregularidades do solo; dispositivos de segurança; dimensões de acordo com a estatura do grupo em estudo; boa durabilidade, mas caso necessite, também apresenta boa manutenção, tendo em vista que os materiais aplicados para a confecção do T5 são de fácil acesso no mercado local e de baixo custo. O T5 também exibiu abertura, frontal e lateral, que facilita a entrada e saída dos resíduos durante o processo de coleta e descarga dos materiais coletado. Além disso, o transporte serve como "outdoor" móvel, fazendo propaganda de estabelecimentos comerciais, servindo como uma renda extra aos associados.

Diante do uso do T5, os trabalhadores de materiais recicláveis associados à ARENSA, afirmaram ter obtido melhora na qualidade do trabalho, tais como: diminuição das dores nos membros superiores e inferiores; facilidade de realizar manobras; segurança em parar ou descer com veículo em ruas enladeiradas; comodidade ao colocar e retirar resíduos no transporte.

\section{Conclusões}

Constatou-se que para a coleta e o transporte de resíduos sólidos, os catadores de materiais recicláveis associados à ARENSA disponham de veículos de tração humana, confeccionados sem medidas justificadas e com material inapropriado denominados de veículos T1, T2 e T3. Observando-se e analisando-se as limitações das tecnologias empregadas pelos catadores de materiais recicláveis associados à ARENSA, foram

\section{POLÊM!CA | Revista Eletronica da Ueij}


desenvolvidos dois veículos para a coleta e o transporte dos resíduos recicláveis coletados (T4, T5).

Para o desenvolvimento dos veículos T4 e T5, ponderou-se as necessidades do grupo e os parâmetros ergonômicos, sobretudo no que se refere à redução do esforço físico ao longo da jornada de trabalho. Nesses veículos, foram implantados: rodas adequadas; sistema de frenagem; itens de segurança; kit de higiene; aberturas que facilitam a entrada e saída de materiais e encaixam na mesa de triagem. Essas estruturas foram confeccionadas em material resistente e leve, desmontável, com medidas adaptadas aos usuários, sendo capaz de realizar a coleta de $360 \mathrm{~kg}$ de resíduos de uma só vez.

O veículo T5 foi produzido com pegas de aço móvel com design e em polímero, freios tipo alavanca, com as seguintes dimensões: 1,4 $\mathrm{m}$ de largura, 2,4 $\mathrm{m}$ de comprimento e 1,5 m de altura, apresentou, quando seco, peso de $86 \mathrm{~kg}$, com capacidade para transportar 180 $\mathrm{kg}$ e menor demanda de esforço físico para conduzi-lo, o qual foi reduzido devido às três rodas utilizadas, sendo as duas traseiras de motocicleta e a dianteira de Levorin para carrinho de mão.

As tecnologias projetadas e avaliadas neste estudo, além de possibilitarem melhores condições de trabalho, diminuição do esforço físico e redução de impactos negativos sobre a saúde, contribuíram para o aumento da renda mensal dos catadores de materiais recicláveis da ARENSA (39\%) e favoreceram o recolhimento de maior quantidade de resíduos (12\%).

Portanto, o investimento em tecnologias sociais para o exercício profissional de catadores de materiais recicláveis é importante tanto para a valorização profissional desses trabalhadores, como para a sua participação efetiva na Política Nacional de Gestão Integrada de Resíduos Sólidos.

\section{Referências}

ALEXANDER, C.; JOSHUA, R. Economies of recucling: The global transformation of materials, values and social relations. Journal Article, 2012.

ALENCAR, M. C. B.; CARDOSO, C. C. O.; ANTUNES, M. C. Condições de trabalho e sintomas relacionados à saúde de catadores de materiais recicláveis em Curitiba. Rev. Terapia Ocupacional. Univ. São Paulo, v. 20 , n. 1, p. 36-42, jan./abr, 2009.

ABNT. NBR 7195. Cores para segurança. Junho de 1995. Disponível em <http://pt.scribd.com/doc/91037917/NBR-7195-1995-Cores-Para-Seguranca. Acesso em 29 de março de 2013. 
ABNT. NBR 14644. Sinalização vertical viária - Películas - Requisitos. Janeiro de 2001. Disponível em: <http://pt.scribd.com/doc/60464452/NBR-14644-Sinalizacao-vertical-viaria-Peliculas-Requisitos>. Acesso em: 29 de março de 2013.

BERENGUEL, O. L. Nas tramas do sub-emprego: precarização do trabalho dos catadores de recicláveis na dinâmica territorial de Bragança Paulista-SP. Revista Resgate. v. 19, n. 21, p. 71-84, 2011.

BRINGHENTI, J. R.; ZANDONADE, E. GUNTHER, W. M. R. Selection and validation of indicators for programs selective collection evaluation with social inclusion. Resources, Conservation and Recycling, 2011.

BROBERG, O. Workspace design a framework for the contribution of ergonomics to production engineering. São Carlos. 2010. Palestra proferida no XXX Enegep (Encontro Nacional de engenharia de produção).

CASTILHOS JR, A. B.; RAMOS, N. F.et.al. Catadores de materiais recicláveis: análise das condições de trabalho e infraestrutura operacional no Sul, Sudeste e Nordeste do Brasil. 2013. Disponível em: <http://www.scielo.br/Acesso 07/01/2014>.

FOGLIATTO, F. S.; GUIMARÃES, L. B. M. Design Macroergonômico. Abergo, 1999.

DUL, J.; WEERDMEESTER, B. Ergonomia Prática. Tradução de Itiro Iida. 2 ed. São Paulo. Edgard Blücher, 2004.

HOLMBERG, K.; ANDERSSON, P.; ERDEMIR, A. Global energy consumption due to friction in passenger cars. Tribology international, Argonne, 2011.

LAGARINHOS, C. Reciclagem de pneus: Análise do impacto da legislação ambiental através da logística reversa. Tese (Doutorado). USP-São Paulo. 2011.

MACCARINI, A.C.; OLIVEIRA, G. A.; MACCARINI, N. M.; ANDRADE, J. B. L. An efficient approach for selective collection made by scavengers for transportation logistics of recyclable materials. Independent Journal of Management \& production, v. 5, n. 1, 2014.

MARCONI, M. A; LAKATOS, E. M. Técnicas de Pesquisa: planejamento e execução de pesquisas, amostragens e técnicas de pesquisa, elaboração, análise e interpretação de dados. 4 ed. São Paulo: Atlas, 1999.

MEDOLA, F. O.; PASCHOARELli, L. C.; SIlVA, D. C.; ELUI, V. M.C.; FORTULAN, C. A. Forças de contato na interface mao-aro propulsor de cadeiras de roda: Implicações ao design ergonômico. Anais. $14^{\circ}$ Congresso Internacional de Ergonomia e Usabilidade de Interfaces Humano. São Luiz-MA, 2014.

MENDONÇA, C.; LOBO, F. J.; MAGEN, J. Benefícios de veículos não motorizados para uso comerciais. In: VII INTRASS- Exposição internacional de transportes e trânsito. Rio de Janeiro, 2011

OLIVEIRA, F. G. Processos de Trabalho e produção de vínculos sociais: Eficiência e Solidariedade na triagem de materiais recicláveis. Dissertação (Mestrado em Engenharia de Produção). Belo Horizonte-MG: UFMG, 2010.

PEREDO, AM; MCLEAN, M. Social entrepreneurship: A critical review of the concept. Journal of World Business, v. 41, n. 1, p. 56-65, 2011.

REFSGAARD, K.; MAGNUSSEN, K. Household behaviour and attitudes with respect to recycling food waste e experiences from focus groups. J. Environ. Manage, v. 90, p. 760-771, 2009.

RIBEIRO, L. A; SILVA, M. M. P; LEITE, V. D; SILVA, H. Educação ambiental como instrumento de organização de catadores de materiais recicláveis na Comunidade Nossa Senhora Aparecida, Campina GrandePB. Revista de BioFar, v.5, n.2, 2011.

\section{POLÊM!CA | Revista Eetrônica da veri}


SILVA, E.H; SILVA, M. A; NASCIMENTO. J. M; JUSTINO. E.D, SILVA, M. M. P. Acondicionamento e destinação final dos resíduos sólidos de serviço de saúde gerados pelos portadores de diabetes mellitus, num bairro de Campina Grande-PB. Anais. Congresso Brasileiro de Gestão Ambiental. Goiânia: ABES, 19 a 22 de novembro/2012.

SILVA, M. M. P. Educação Ambiental para o Reconhecimento e Valorização de catadores de materiais recicláveis; estratégia para a gestão integrada de resíduos sólidos. Relatório Técnico. (Apresentado a Próreitora de Extensão e Assuntos Comunitários). Campina Grande-PB: UEPB, 2009.

THIOLLENT, M. Metodologia da pesquisa-ação. 16ªed. São Paulo: Cortez, 2008.

Recebido em: 15/06/2015.

Aceito em: 14/09/2015.

\begin{abstract}
Anexos
Roteiro para observação direta, visando o levantamento das tecnologias utilizadas no exercício profissional dos catadores de materiais recicláveis associados à ARENSA (Associação de Catadores de Materiais Recicláveis da Comunidade Nossa Senhora Aparecida).
\end{abstract}

\title{
1. Coleta de materiais recicláveis
}

a) Forma de coleta dos materiais recicláveis

b) Número de residências envolvido por coleta diária e mensal

c) Instrumentos utilizados para a coleta de material reciclável

d) Limitações referentes aos instrumentos usados para coleta do material reciclável. Meios de transportes utilizados

e) Impactos sobre a saúde do trabalhador

f) Mudanças apontadas pelos catadores de materiais recicláveis

2. Transporte dos materiais recicláveis

a) Meios de transportes utilizados para o deslocamento do material coletado

b) Percurso realizado diariamente

c) Quantidade de material transportada por transporte

d) Quantidade de material coletada diariamente e mensalmente

e) Limitações em relação aos meios de transportes utilizados

f) Impactos sobre a saúde do trabalhador

g) Mudanças apontadas pelos catadores de materiais recicláveis

\section{Triagem dos materiais recicláveis}

a) Metodologia aplicada para a triagem do material coletado

b) Instrumentos utilizados para a coleta de material reciclável

c) Limitações observadas no processo de triagem

d) Impactos sobre a saúde dos trabalhadores

e) Mudanças apontadas pelos catadores de materiais recicláveis

\section{POLÊM!CA | Revista Eletronica da Ueji}

Rua São Francisco Xavier, 524, $2^{\circ}$ andar - BL D, sl 2025 - Maracanã 


\section{Acondicionamento dos materiais recicláveis}

a) Metodologia aplicada para o acondicionamento do material coletado

b) Instrumentos utilizados para o acondicionamento material coletado

c) Período de acondicionamento

d) Limitações observadas no processo acondicionamento

e) Impactos sobre a saúde dos trabalhadores

f) Mudanças apontadas pelos catadores de materiais recicláveis

\section{Comercialização dos materiais recicláveis}

a) Quantidade e tipos de materiais comercializada e os respectivos valores comerciais dos últimos 05 meses

b) Frequência e forma de venda

c) Renda obtida pelos catadores de materiais recicláveis associados à ARENSA nos últimos 05 meses

d) Destino dos materiais recicláveis

e) Limitações identificadas no processo de comercialização

f) Mudanças apontadas pelos catadores de materiais recicláveis

g) Impactos sobre a saúde dos trabalhadores.

Roteiro para aplicação de entrevista semiestruturada, visando o levantamento das tecnologias utilizadas no exercício profissional dos catadores de materiais recicláveis associados à ARENSA (Associação de Catadores de Materiais Recicláveis da Comunidade Nossa Senhora Aparecida).

a) Em relação ao transporte e à triagem, o que mais prejudica o seu exercício profissional?

b) Durante a coleta, quais são as principais dificuldades para manusear os transportes utilizados?

c) O que pode ser alterado nos transportes que você usa atualmente para minimizar as dificuldades enfrentadas?

d) Em relação à triagem quais são os principais problemas que você encontra? Os transportes interferem nesse processo?

e) O que poderia ser feito para amenizar este desconforto?

f) Quando você está executando a triagem do material coletado, você sente algum tipo de desconforto?

Roteiro para avaliação dos transportes já utilizados pelos catadores de materiais recicláveis associados à ARENSA

1. Transportes utilizados

a) Tipos de transportes e os materiais usados para construção

b) Custo de construção

c) Capacidade volumétrica

d) Aspectos relacionados à durabilidade e operação

e) Demanda de esforço físico

f) Vulnerabilidade a acidentes

g) Limitações registradas em relação aos transportes já utilizados

h) Mudanças apontadas pelos catadores de materiais recicláveis

i) Síntese das variáveis que serão investigadas

\begin{tabular}{|c|c|c|c|c|c|}
\hline \multirow{2}{*}{ Variáveis } & \multicolumn{2}{|c|}{ Meios de transportes já utilizados (TA) } & \multicolumn{2}{c|}{ Transporte em desenvolvimento (TN) } \\
\cline { 2 - 6 } & TA1 & TA2 & TA3 & TN1 & TN2 \\
\hline $\begin{array}{c}\text { Tipo de material } \\
\text { usado para } \\
\text { carroceria }\end{array}$ & & & & & \\
& & & & & \\
\hline
\end{tabular}

\section{POLÊM!CA | Revista Eletronica da Ueij}

Rua São Francisco Xavier, 524, $2^{\circ}$ andar - BL D, sl 2025 - Maracanã

Tels.: +55 $212334-0888$ / 0887

http://www.labore.uerj.br/ - laboreuerj@yahoo.com.br 


\begin{tabular}{|c|l|l|l|l|l|}
\hline Tipo de pneus & & & & & \\
\hline $\begin{array}{c}\text { Capacidade } \\
\text { volumétrica }\end{array}$ & & & & & \\
\hline $\begin{array}{c}\text { Custo de } \\
\text { construção }\end{array}$ & & & & & \\
\hline $\begin{array}{c}\text { Facilidade de } \\
\text { manuseio }\end{array}$ & & & & & \\
\hline Riscos de acidentes & & & & & \\
\hline
\end{tabular}

A: antigo N: Novo T: Transporte

Identificação dos impactos positivos proporcionados a partir do desenvolvimento das tecnologias de transporte e triagem

1. Com relação aos itens abordados na tabela, classifique como péssimo, ruim, bom e excelente.

2. A partir do uso do T5, os desconfortos físicos, anteriormente citados, persistiram?

3. Ainda existe algo a ser melhorado no T5?

4. Houve melhora na qualidade de trabalho a partir do uso do T5? Quais? 